\title{
Life Cycle Modelling of the Impact of Coal Quality on Emissions from Energy Generation
}

\author{
Lukasz Lelek ${ }^{1, *}$ and Joanna Kulczycka ${ }^{2}$ \\ 1 Mineral and Energy Economy Research Institute, Polish Academy of Sciences, Wybickiego 7A Str., \\ 31-261 Cracow, Poland \\ 2 Faculty of Management, AGH University of Science and Technology, 30-067 Cracow, Poland; \\ kulczycka@meeri.pl \\ * Correspondence: lelek@meeri.pl
}

Received: 30 December 2019; Accepted: 17 March 2020; Published: 23 March 2020

\begin{abstract}
This paper presents a model combining the LCA (Life Cycle Assessment) of fossil fuel extraction with its quality parameters and related $\mathrm{CO}_{2}, \mathrm{SO}_{2}$ and dust emissions at the stage of the combustion process. The model which was developed aims to identify the environmental impact of the processes of electricity production from selected energy carriers over their whole life cycle. The model takes into account the full LCA of fossil fuel extraction (of both hard and brown coal), its enrichment and fuel production as well as the environmental impact associated with emissions introduced into the air at the stage of electricity generation based on the fuels evaluated. Such an approach allows one to determine the fuel quality parameters that affect the environmental impact of energy production based on an LCA of mining and assigns the degree of environmental impact involved in particular production processes. Overall, the results obtained based on the proposed model permit the identification and prioritisation of the individual processes in the electricity generation life cycle which contribute the highest share in the general environmental impact indicator, having taken into account the modelling of the quality of the fuels used (calorific value, ash and sulphur content).
\end{abstract}

Keywords: LCA; coal; energy; environmental impact; modelling

\section{Introduction}

Decarbonisation of the global economy is now an important trend, underlined in many policies, especially in the European Union, which focus on achieving the Sustainable Development Goal, especially 13, which includes actions aimed at integrate climate change measures into national policies, strategies and planning. The European Commission introducing the European Green Deal sets ambitious objectives in various sectors clearly targeting climate policy and aim to make the EU climate neutral by 2050. In practice, this means no net emissions of greenhouse gases in 2050 as well as further efforts to improve energy efficiency, large-scale electrification and uptake of renewable energy sources. Sustainable production of electricity and heat will play a crucial part in this transition. However, the coal based energy generation, as a major energy carrier, is currently responsible for $25 \%$ of anthropogenic greenhouse gas (GHG) emissions, as well as other negative impacts on the environment and on human health [1]. Taking into account the high dependence of the global economy on fossil fuels including coal, solutions using these fuels, which at the same time reduce the associated environmental impact, are equally as desirable as the introduction of decarbonisation policies. For countries such as Poland, which is the largest producer of coal in the EU and also one of the EU's coal consumers, the transition to a total abandonment of the use of coal may take many years. According to Polish strategic documents and forecasts, this is mainly related to energy security and other economic and social considerations. Therefore, there are many projects and analyses in Poland which focus on the reduction of the impact 
of coal-based electricity generation on the environment, including on the implementation of water-coal slurry [2], blue coal [3], coal gasification [4] or carbon capture and storage (CCS) technology [5] as well as reducing the emission of heavy metals like $\mathrm{Hg}$ [6].

Use of better-quality fossil fuels in the field of caloric value or sulphur and ash content is also one of the recommendations to avoid, minimise and offset emissions from coal-based electricity generation. Most fractions of bituminous coal have a carbon content (with respect to the original substance) of between $60 \%$ and $75 \%$. The average content, which can vary from year to year, ranges between $65 \%$ and $66 \%$. Bituminous coal lying within the lower range, up to a carbon content of about $56 \%$, and a net calorific value of no more than $22 \mathrm{MJ} / \mathrm{kg}$, is referred to as low-grade coal [6]. A wide range of physical and chemical properties of coal (including heat value, volatile matter, carbon content, sulphur content, moisture, ash, etc.) determine the price of coal, as well as the environmental aspects of their use There are a number of standards available to classify coal with different qualities and usages [7]. LCA (Life Cycle Assessment) results show that, in general, coal type is the dominant factor in determining the potential environmental impact. The Global Warming Potential (GWP) is mainly influenced by the heating value (e.g., lignite combustion has the highest value in GWP for the same unit of energy produced due to the low heating value and higher consumption compared to hard coal with a higher calorific value [8]. Therefore in the full life cycle, it is not only the phase of coal consumption that has to be considered in detail, but also the environmental impact associated with its extraction and processing. Depending on these processes, as well as the type of technology and equipment used, the associated environmental impact may vary greatly. However, it usually affects the terrain deformations, changes to water regime, pollution of water and soil as well as the generation of extraction waste. The technological processes involved in underground mining are much more complex than those involved in surface mining. The selection of suitable processing technologies is dependent on many factors, including biological factors related to the geological and mining conditions as well as economic factors (e.g., relating to the quality requirements of the fractions produced). The detailed analysis and assessment of the environmental impact, as well as efforts to minimise the impact throughout the entire life cycle, is of crucial importance for the development of the mining sector. It is also important to consider not only the volume of emissions and waste produced, but also the volume of resources and energy consumed, as well as the long-term plans regarding the methods of re-cultivation of post-mining areas. The environmental impact assessment related to these aspects can then be linked quantitatively and qualitatively to the different parameters of the fuels produced. In this way, information on fuel quality and the associated environmental impacts at the level of their production and use can provide a basis for action to reduce these impacts. However there is still a lack of studies concerning the identification and modelling of the impact on the environment of mining activities over the entire life cycle, including the quality of coal produced. The correlation of calorific value, amount of ash and sulphur content with emissions at the electricity generation stage is well known in the literature, but a combination of these correlations with the LCA mining process, including outputs such as the different quality fuel streams, was proposed for the first time. Therefore, the objective of this paper is to suggest a model approach to the impact of the quality of the fuel extracted on combustion-related emissions and their impact on the environment over the entire life cycle. Thanks to the use of the proposed model, it is possible to assess the influence of fuel produced and its varied quality on the main environmental impacts from its combustion (i.e., emissions of $\mathrm{CO}_{2}$, $\mathrm{SO}_{\mathrm{x}}$ and dust) as well as their influence on individual components of the environment.

As Poland has large resources of hard coal, replacing coal as a major source of thermal energy is a long process that will be spread over many years. Therefore, it is crucial to limit the current environmental impact by the implementation of innovative technologies and the modernisation of currently existing facilities. Nevertheless, such activities are based on appropriate tools to support decision-making processes, including environmental impact assessment as well as LCA. The model may also become the basis for modelling environmental fees resulting from the use of fuels of a particular quality, including $\mathrm{CO}_{2}$ emission fees. Coal comes with a substantially higher emission of $\mathrm{CO}_{2}$ than 
other fossil fuels. To address the challenge of decarbonising the energy sector, emission trading schemes have recently been introduced, mainly in the European Union. Prices of $\mathrm{CO}_{2}$ emission allowances already have an influence on coal markets, which will likely increase in the future. Coal prices vary according to qualities, quantities, transportation costs and other conditions [9]. The implementation of innovative and eco-friendly solutions permits a significant reduction in the negative impact of energy generation from coal combustion [10].

\section{State-Of-the-Art}

A review of the literature related to the use of LCA for the study of the energy sector, either in a holistic approach or as single technologies, indicates its widespread use. However, leading literature positions regarding LCA for fossil fuels focus mainly on assessments of electricity generation processes. The World Energy Council (WEC) report of 2004 may be an example. The report considers each kind of primary energy according to its place of origin and final use. It provides a comparison of different energies based on full life cycle assessments which have been performed in the last 10 to 15 years [11]. More recent work in this area includes the studies of Cui L. et al. [12] and Wang N. et al. [13], but here one can also note that the phase of extraction of fossil fuels is just one of many individual processes under consideration which contribute to a blurring of the results which are significant for the mining industry when compared to other environmental burdens of coal power generation. There are far fewer publications focusing solely on the mining phase and analysing the specific conditions of extraction and its related environmental impact.

One of the largest was carried out by the Environmental Institute (SYKE) Helsinki [14], in which the processes of coal-based electricity generation were assessed. The study covered the extraction and processing of bituminous coal, representing averaged data from mines in Poland and Estonia. On the basis of the results obtained, it was stated that the energy used at the stage of coal extraction and enrichment is responsible for high emissions of heavy metals and the extraction processes for high methane emissions (it was assumed that only about $20 \%$ of the methane released in Polish mines is recovered and used as a fuel). A similar LCA was also carried out in Poland by the Central Mining Institute based on inventory data from 38 hard coal mines [15], where their own calculation model for LCA assessment was used. This consists of an average profile of a model mine with an annual capacity of 2.5 million $\mathrm{Mg}$ of coal, which was subjected to an environmental impact assessment.

Other research on the environmental impact over the life cycle of bituminous coal is linked to surface mining (a cradle to gate analysis). Five opencast mines in the USA were analysed in the work of Ofentse Ditsele and Kwame Awuah-Offei [16]. The study mainly assessed the impact on water consumption, land use, energy use, abiotic resource depletion and climate change. The authors stressed that there is a lack of literature available on the LCA of mining and that the available literature highlights some methodological problems which may be the cause of the small number of LCA studies undertaken in this area. These include, among other issues, problems with the selection of an appropriate functional unit, the boundaries of the system being analysed or the determination of appropriate impact categories reflecting significant environmental problems in the mining industry. In the LCA research on the surface mining of lignite based on high-quality data from 12 mines in Turkey, including nine open-pit mines [17] as well as a study of four South African mines [18], the author underlined the issue that the standard LCA impact categories, such as global warming, ozone depletion, toxicity for humans, ecotoxicity of water, acidification and eutrophication, are insufficient to describe the environmental impact of mineral resource extraction. Such categories as land take, water consumption, energy use and depletion of resources were proposed as the most significant, and equivalent to the LCA analysis of the mining sector [19]. There is also a continuing debate among practitioners and scientists on the principles of various models and LCA indicators developed in the last 30 years referring to the depletion of resources category. A compromise on which model represents the best state-of-the-art model has not yet been reached [20]. The most popular model is the so-called abiotic depletion potential (ADP). It relies on the analysis of the current use of resources (extraction 
rate, present use) in relation to balanced resources. Many LCA methods currently in use are based on this model. It is not fully adequate; however, for example, for the assessment of the depletion of existing fossil fuel deposits as it provides little information related to the environmental consequences of the extraction processes used [21,22].

In terms of the models developed using LCA methodology (e.g., for the sustainable development of mines), attention should be paid to the study of Burchart-Korol D. et al. [23]. It used detailed models of environmental assessment that have been developed using LCA, while cost-benefit analysis (CBA) was proposed for the economic aspects. The algorithm thus developed allows the comparison of individual mining plants taking into account the main aspects of sustainable development, including the environmental, economic and social aspects. Another model of the eco-efficiency assessment of mining production processes was also shown by Czaplicka-Kolarz K. et al. [24]. The model-based result thus obtained was proposed as one of the key performance indicators (KPI) for bituminous coal mines, applicable to decision-making support processes (e.g., the investment decisions in mining enterprises). A combined methodology (i.e., a combination of LCA and TEC (Thermo-Ecological Cost) for the assessment of the fossil fuel extraction system in its energo-ecological aspects was also suggested in the study by Stanek W. et al. [25]. In this case, the boundaries of the system have been extended to also include the TEC ratings for coal use technologies. Three options were taken into account in this assessment: power plant, CHP plant and heat plant. This level of assessment showed that the type of energy conversion process can strongly influence the final TEC results for different coals.

It was noted that there is no work based on LCA methodology in the literature which models the impact of mining processes taking into account the quality of the fuel obtained. The only relevant results referring to the market value of high- and low-quality fuels are also shown in Mangena S.J. and Brent A.C's study, where four South African mines were examinedThis undoubted gap is the subject of the model presented in this paper.

\section{Model}

As part of the model that was developed for assessing the impact of fossil fuels on emissions from electricity generation and their environmental impact, the technical aspects of the processes for extracting fossil fuel were integrated (bituminous coal and lignite) with the quality of the fuels obtained.

The limits of the model were defined as the process of electricity generation from the phase of extraction and production of fossil fuels (without preparation work and infrastructure) to the phase of energy generation in a power plant (without the phases of energy distribution and transport to the end user). As the main assumption of the model is the assessment of the fossil fuel extraction phase and the allocation of impacts to the type and quality of fuel produced, the model was divided into two separate modules (i.e., a mining module and an energy module). Its structure is presented in Figure 1. However, each of the modules is described separately below. The figure shows a model based on the separate analysis of two fossil fuels, hard coal and lignite.

In the case of the mining module, the environmental impact assessment takes into account the full LCA analysis, including all potential direct impacts in the life cycle of the mine and coal processing plants (i.e., emissions to air, water and soil), as well as waste generated and indirect impacts resulting from the supply chain of the materials consumed, water, energy and fuels. The results obtained from the mining module, in combination with the quality parameters of the fuel streams produced, are the basis for the evaluation and calculation of emissions at the level of power plants in accordance with the procedure described in point 3.2. 


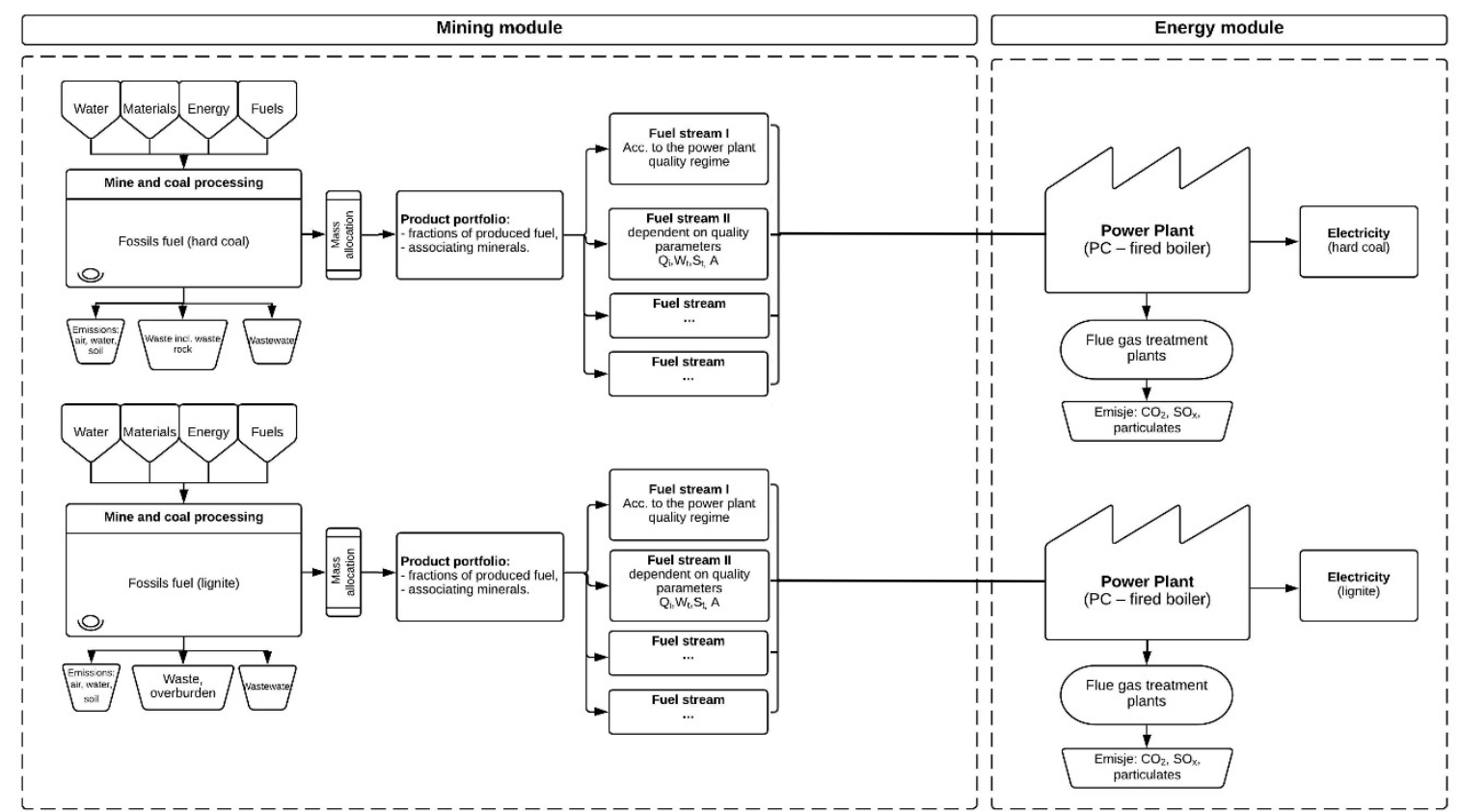

Figure 1. The structure of the model of the environmental impact assessment of electricity generation processes from selected carriers in Polish conditions $\left(\mathrm{Q}_{\mathrm{i}}\right.$ - calorific value, $\mathrm{W}_{\mathrm{t}}$-total water, $\mathrm{A}$-ash content, $\mathrm{S}_{\mathrm{t}}$-total sulphur content, $\mathrm{PC}$-pulverised coal).

\subsection{Mining Module}

The mining module forms the basis underlying and the main component of the model that was developed. Its objective is to analyse the fossil fuel extraction phase as the first stage of the electricity generation life cycle. The mining module was created with the use of full LCA analysis considering all direct and indirect technological aspects resulting from the supply chain, with their possible impacts on the environment.

The model-based analysis; therefore, begins with the LCA of a selected mining enterprise. The model takes into account the processes of coal extraction and processing. Due to limited access to data on the opening up of the deposit, preparation works and infrastructure used, this data was not included in the model in accordance with \#3.18 PN-EN ISO 14040:2009. The first phase (Figure 2) of the model describes the so-called portfolio of products representative of an individual enterprise. The scope of the portfolio includes the production of a specified (in quality and quantity) fuel within a specific year(s).

The next step is the quantification of products (i.e., breaking them down by parameters such as calorific value $\left(\mathrm{Q}_{\mathrm{i}}\right)$, ash content $(\mathrm{A})$ and sulphur content $\left(\mathrm{S}_{\mathrm{t}}\right)$. Further analysis of the energy modules using the model will be based on these parameters.

A set of individual processes with materials, energy and fuel flows as well as emissions and waste should represent a defined portfolio. Therefore, the next steps in modelling are in accordance with the stages of LCA analysis presented in the PN-EN ISO 14040:2009 standard (i.e., the analysis of the inventory (LCI) and the analysis of a potential environmental impact (LCIA). For this it is necessary to collect data from the mining enterprise being evaluated. The next step is including LCIA analysis with the assignment of data from the set of inputs and releases to the individual environmental impact categories and category indicators in order to identify these impacts. The LCIA phase also provides information for the life cycle interpretation phase. 


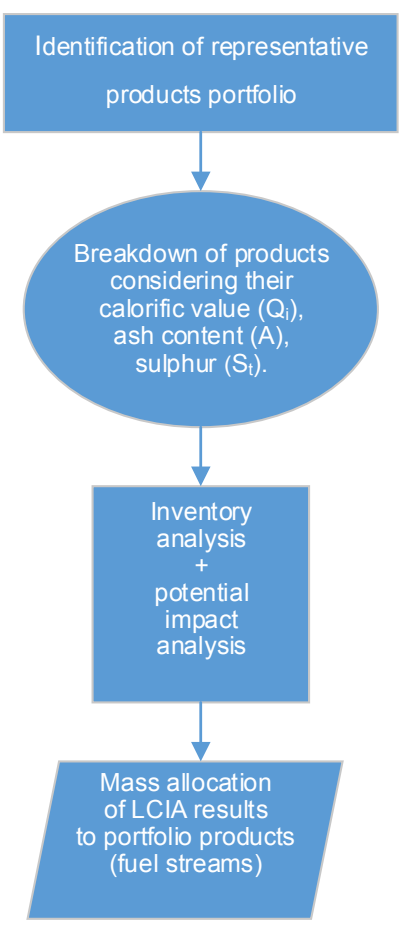

Figure 2. Algorithm of the procedure for the mining module in the model (LCIA-Life Cycle Impact Assessment, $\mathrm{Q}_{\mathrm{i}}$-calorific value, $\mathrm{A}$-ash content, $\mathrm{S}_{\mathrm{t}}$-total sulphur content).

For the so-called multi-product processes, it is necessary to use the allocation procedure for the results in accordance with the PN-EN ISO 14040: 2009 standard, which consists in breaking down the results for individual fuel streams in such a way as to reflect basic physical dependencies. Mass allocation was used in the model to provide for the comparison of the results obtained during the LCIA analysis stage with the products identified in the portfolio (fuel streams).

Based on the results thus obtained, in the next (energy module) stage the quantities of potential emissions into the atmosphere resulting from the energy-related combustion process will be calculated for each of the fuel streams identified.

\subsection{Energy Module}

The objective of this module is to combine the quality parameters of fuel streams and their potential environmental impact calculated in the mining module with the potential environmental impact of the $\mathrm{CO}_{2}, \mathrm{SO}_{2}$ and dust emissions generated at the electricity generation stage. For this purpose, the calorific value $\left(Q_{i}\right)$, ash $(A)$ and sulphur content $\left(S_{t}\right)$ of the individual fuel streams have been used. These dependencies require the assumption of adequate combustion technology as well as flue gas treatment technologies (Figure 3). These technologies will determine the quantities of emissions released from the combustion process into the environment. The energy module is; therefore, a simplified black box relating solely to the three types of emissions. It does not take into account the use of consumables (except of fuel streams), other emissions and waste and sewage management.

For the calculation of individual emissions, appropriate formulae have been adopted [26]. Mass balance assuming complete combustion was used in order to determine the carbon emission indicator and the potential $\mathrm{CO}_{2}$ emission indicator:

$$
\begin{gathered}
\mathrm{WE}_{\mathrm{c}}=10^{6} \times \frac{\mathrm{c}}{\mathrm{W}_{\mathrm{o}}} ; \\
\mathrm{WE}_{\mathrm{CO}_{2} \max }=\frac{44}{12} \times \mathrm{WE}_{\mathrm{c}},
\end{gathered}
$$


where:

$\mathrm{WE}_{\mathrm{c}}$-carbon emission indicator $[\mathrm{g} / \mathrm{GJ}]$,

$\mathrm{WE}_{\mathrm{CO} 2 \mathrm{max}}$ - maximum emission indicator $\mathrm{CO}_{2}[\mathrm{~g} / \mathrm{GJ}]$,

c-carbon content in fuel $[\mathrm{kgC} / \mathrm{kg}$ of fuel $]$

$\mathrm{W}_{0}$-fuel calorific value $[\mathrm{MJ} / \mathrm{kg}]$

44/12-molar ratio of $\mathrm{CO}_{2}$ and $\mathrm{C}$.

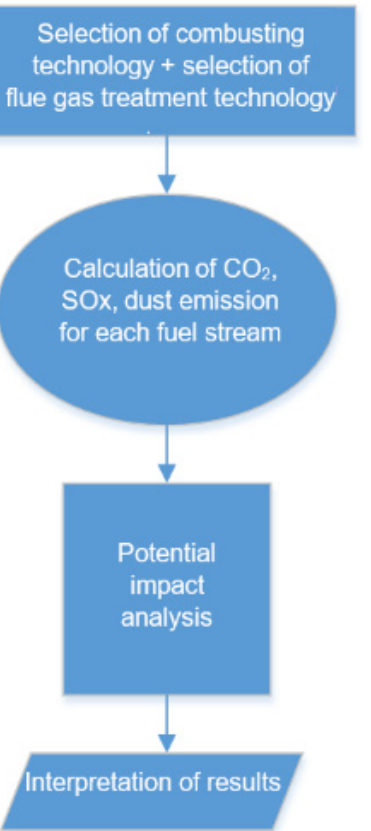

Figure 3. Algorithm of the procedure for the model's energy module.

Considering the strong relationship between the calorific value and carbon content in fuel, this can be calculated from the equation:

$$
c[\%]=0.1 \mathrm{~W}_{\mathrm{o}} \times\left(\mathrm{a}-\mathrm{b} * \mathrm{~W}_{0}\right),
$$

where:

c-pure carbon content in fuel,

$\mathrm{W}_{0}$-fuel calorific value $[\mathrm{MJ} / \mathrm{kg}]$,

$\mathrm{a}, \mathrm{b}-$ carbon emission factors as a function of fuel calorific value $\left(\mathrm{W}_{0}\right)$

In order to consider the proportion of unoxidised carbon, IPCC recommends correcting the indicators according to the formula:

$$
\mathrm{WE}_{\mathrm{CO}_{2}}=\mathrm{WE}_{\mathrm{CO}_{2} \max } \times\left(1-\frac{\mathrm{r}[\%]}{100}\right),
$$

where:

$\mathrm{r}$-unoxidized carbon.

For example, for dust boilers fired by coal, the amount of unoxidised carbon is below $2 \%$ (approx. $1 \%$ on average). In the case of large combustion plant, the $\mathrm{CO}_{2}$ emissions should also be corrected by the amount of coal that stays in the waste after combustion (i.e., in fly ash and slag). However, in 
order to determine the amount of such coal, analyses of the chemical content of residues are necessary. Average values are available in the literature and can be used when substituted with the formula:

$$
\mathrm{r}[\%]=\left(\frac{\mathrm{c}_{\mathrm{pl}}}{100 \mathrm{c}_{\mathrm{pl}}} \times \mathrm{u}_{\mathrm{p}}+\frac{\mathrm{c}_{\mathrm{z}}}{100 \mathrm{c}_{\mathrm{z}}} \times\left(100 \mathrm{u}_{\mathrm{p}}\right)\right) \times \frac{\mathrm{p}}{\mathrm{c}^{\prime}}
$$

where:

$\mathrm{r}$ - unoxidized carbon,

$\mathrm{c}_{\mathrm{pl}}$-average content of combustible elements captured in fly ash [\%],

$c_{\mathrm{Z}}$-average content of combustible elements in slag [\%],

$\mathrm{u}_{\mathrm{p}}$-indicator of dust dissipation,

$\mathrm{p}$-average content of ash in coal [\%],

c-pure carbon content in coal [\%].

In order to estimate the quantities of dust emitted, the following dependency was used:

$$
\mathrm{WE}_{\text {dust }}[\mathrm{g} / \mathrm{Mg}]=(1-\alpha) \times \rho \times \mu_{\mathrm{p}} \times \frac{100 \eta_{0} \times \beta_{0}}{100 c_{\mathrm{p}}} \times 10^{2},
$$

where:

$\mathrm{WE}_{\text {dust }}$-indicator of dust emissions,

$\alpha$-coefficient of chemical contraction (0-0.1) —specifies the decrease in weight of mineral substance $t$ in combustion due to its partial transformation to gas $(0-10 \%)$. The theoretical contraction coefficient for the complete combustion of liquid fuel is expressed by an equation

$\rho$-ash content in fuel [\%],

$\mu_{\mathrm{p}}$-dissipation of ash [\%]—depends on the type of hearth, grain content, velocity of air flow to the hearth.

$\eta_{0}$-effectiveness of dedusting equipment [\%],

$\beta_{0}$-availability of dedusting equipment (0-1),

$\mathrm{c}_{\mathrm{p}}-$ content of combustible parts in dust [\%].

The volume of $\mathrm{SO}_{\mathrm{x}}$ emissions can be calculated using the mass balance:

$$
\mathrm{We}_{\mathrm{SO}_{\mathrm{x}}}\left[\frac{\mathrm{g}}{\mathrm{GJ}}\right]=2 \times \frac{\mathrm{s}}{\mathrm{W}_{0}} \times(1-\mathrm{r}) \times 10^{6},
$$

where:

$\mathrm{s}$ - content of sulphur in fuel $[\mathrm{kg} / \mathrm{kg}$ of fuel],

$\mathrm{W}_{0}$-fuel calorific value $[\mathrm{MJ} / \mathrm{kg}]$,

$\mathrm{r}$-contribution of sulphur residue to ash,

2 -molar ratio of $\mathrm{SO}_{2}$ and $\mathrm{S}$.

Another aspect to be considered in the case of the emission of sulphur oxides is the flue gas desulphurisation system together with its efficiency. The emission of sulphur oxides can be calculated from the formula:

$$
\mathrm{WE}_{\mathrm{SO}_{x}}\left[\frac{\mathrm{g}}{\mathrm{GJ}}\right]=2 \times \frac{\mathrm{s}}{\mathrm{W}_{0}} \times(1-\mathrm{r}) \times(1-\eta \times \beta) \times 10^{6},
$$

where:

$\eta$-effectiveness of method of flue gas desulphurisation,

$\beta$-availability of desulphurisation plant. 
Emissions calculated in this way at the level of the energy module are then subjected to LCIA assessment in order to determine their environmental impacts and their share in the indicators of individual impact categories. These results can then be linked to the LCA results for the fuel streams identified from the mining module. This way, the final results based on the entire model may be compared to a functional unit reflecting 1 MWh of electricity produced. This, in turn, enables analysis of the sensitivity of changes in environmental impact with regard to electricity generation processes depending on the quality of the fuels used.

\section{Conclusions}

With reference to the aforementioned aspects, a research problem was presented which is aimed at identifying the potential for modelling the quality of fuel used with its environmental burdens at the level of power plants. The model which was created will allow the identification of the environmentally weakest stages in the entire supply chain for fuel streams which vary in terms of quality. In the model, the fuel streams are selected based on the changeable parameters of the fuel (i.e., its calorific value as well as sulphur and ash content). It is possible, based on the proposed model, to compare the potential impacts of individual fuel streams taking into account $\mathrm{CO}_{2}, \mathrm{SO}_{\mathrm{x}}$ and dust created during the combustion stage. Such a comparative analysis may become a basis for the assessment of the sensitivity of a potential impact of electricity generation with reference to changes in the parameters of coal quality.

The results of the model provide a background for a deeper analysis of fuel streams, making it possible to identify the fuels with the lowest environmental impact in the stage of energy generation. These results may, therefore, become the foundation for environmental optimisation of fuel production at the level of mining enterprises, as well as modelling environmental fees related to the stage of coal consumption. This is particularly relevant from the point of view of a new industrial strategy for a green and digital Europe, which support change towards a competitive, green and digital industry [27]. Therefore, the presented model based on the LCA can be an appropriate tool to identify and make changes in order to pursue the strategy's objective. The energy sector in future will need to be more flexible, with more diversified production mix. However, as more renewable energies are deployed, the issue of intermittency is becoming ever more critical for the stability of the energy system. Thus, stable energy sources, including coal, can still be an important part of this system. That is why it is so important to take action also in this sector to support change towards competitive, green and digital industry. The redesign of existing coal-based energy systems, including eco-design aspects, can contribute to change towards more sustainable energy production from coal. LCA, as one of the tools of eco-design, enables new idea generation and opportunity for innovation. Taking a life cycle approach, you can use multiple strategies in multiple life cycle phases to improve environmental performance of modernised technological systems. Thus, the data obtained using the proposed model may be the basis of recommendations or new technological solutions reducing the impact on the environment of electricity generation over its entire life cycle. The model developed suggests solutions that make it possible to compare and quantify the impact of the quality parameters of coal from selected mining enterprises (i.e., the impact of calorific value (Ar) and sulphur (Str) on the environment in electricity generation processes over their entire life cycle).

Overall, the results obtained based on the proposed model allow the identification and prioritisation of individual processes in the life cycle of electricity generation, with the highest share found in the general environmental impact indicator, having taken into account the modelling of the quality of fuels used. Prioritisation and analysis of these processes in terms of alternative technological solutions may be the basis for the implementation of organisational and technical changes aimed at the preservation of the optimal quality of these processes.

Author Contributions: Conceptualization, L.L. and J.K.; Methodology, L.L.; Validation, L.L.; Formal Analysis, L.L.; Investigation, L.L.; Resources, L.L.; Data Curation, L.L.; Writing-Original Draft Preparation, L.L.; Writing-Review 
\& Editing, L.L.; Visualization, L.L.; Supervision, J.K. All authors have read and agreed to the published version of the manuscript.

Funding: This research received no external funding.

Conflicts of Interest: The authors declare no conflict of interest.

\section{References}

1. Resource Panel. Available online: https://www.resourcepanel.org/reports/green-energy-choices-benefitsrisks-and-trade-offs-low-carbon-technologies-electricity (accessed on 30 December 2019).

2. Staron, A.; Kowalski, Z.; Staroń, P.; Banach, M. Studies on CWL with glycerol for combustion process. Environ. Sci. Pollut. Res. 2019, 26, 2835-2844. [CrossRef] [PubMed]

3. Niesler, M.; Stecko, J.; Gierad, D.; Stelmach, S.; Nowak, M. The assessment of the possibility of the "blue coal" utilization in the iron ore sintering process. Prace Instytutu Metalurgii Żelaza 2019, 69, 31-43.

4. GIG. Available online: https://www.gig.eu/en/news/test-underground-coal-gasification-ucg-process (accessed on 30 December 2019).

5. Labus, K.; Tarkowski, R.; Wdowin, M. Assessment of $\mathrm{CO}_{2}$ sequestration capacity based on hydrogeochemical model of Water-Rock-Gas interactions in the potential storage site within the Belchatów area (Poland). Miner. Resour. Manag. 2010, 26, 69-84.

6. Żmuda, R.; Adamczyk, W.; Lelek, L.; Mandrela, S.; Wdowin, M. Innovative technology for the treatment of exhaust gas from mercury as a solution to meet the requirements of the BAT/BREF conclusions in the Polish power industry. Polityka Energetyczna-Energy Policy J. 2017, 20, 103-115.

7. Umweltbundesamt. Available online: https://www.umweltbundesamt.de/sites/default/files/medien/1968/ publikationen/co2_emission_factors_for_fossil_fuels_correction.pdf (accessed on 30 December 2019).

8. Core. Available online: https://core.ac.uk/download/pdf/82794099.pdf (accessed on 30 December 2019).

9. Energycharter. Available online: https://www.energycharter.org/fileadmin/DocumentsMedia/Thematic/ Coal_Study_2010_en.pdf (accessed on 30 December 2019).

10. Dzikuć, M.; Piwowar, A. Life cycle assessment as an eco-management tool within the power industry. Pol. J. Environ. Stud. 2015, 24, 2381-2385. [CrossRef]

11. World Energy. Available online: https://www.worldenergy.org/assets/downloads/PUB_Comparison_of_ Energy_Systens_using_lifecycle_2004_WEC.pdf (accessed on 30 December 2019).

12. Cui, L.; Li, Y.; Tang, Y.; Shi, Y.; Wang, Q.; Yuan, X.; Kellett, J. Integrated assessment of the environmental and economic effects of an ultra-clean flue gas treatment process in coal-fired power plant. J. Clean. Prod. 2018, 199, 359-368. [CrossRef]

13. Wang, N.; Ren, Y.; Zhu, T.; Meng, F.; Wen, Z.; Liu, G. Life cycle carbon emission modelling of coal-fired power: Chinese case. Energy 2018, 162, 841-852. [CrossRef]

14. Sokka, L.; Koskela, S.; Seppälä, J. Life Cycle Inventory Analysis of Hard Coal Based Electricity Generation; The Finnish Environment: Helsinki, Finland, 2015.

15. Czaplicka-Kolarz, K.; Wachowicz, J.; Bojarska-Kraus, M. A life cycle method for assessment of a colliery's eco-indicator. Int. J. Life Cycle Assess. 2004, 9, 247-253. [CrossRef]

16. Ditsele, O.; Awuah-Offei, K. Effect of mine characteristics on life cycle impacts of US surface coal mining. Int. J. Life Cycle 2012, 17, 287-294. [CrossRef]

17. Şengül, H.; Bayrak, F.; Köksal, M.A.; Ünver, B. A cradle to gate life cycle assessment of Turkish lignite used for electricity generation with site-specific data. J. Clean. Prod. 2016, 129, 478-490. [CrossRef]

18. Mangena, S.J.; Brent, A.C. Application of a Life Cycle Impact Assessment framework to evaluate and compare environmental performances with economic values of supplied coal products. J. Clean. Prod. 2016, 14, 1071-1084. [CrossRef]

19. Awuah-Offei, K.; Adekpedjou, A. Application of life cycle assessment in the mining industry. Int. J. Life Cycle Assess. 2011, 16, 82-89. [CrossRef]

20. Klinglmair, M.; Sala, S.; Brandao, M. Assessing resource depletion in LCA: A review of methods and methodological issues. Int. J. Life Cycle Assess. 2014, 19, 580-592. [CrossRef]

21. Durucan, S.; Korre, A.; Munoz-Melendez, G. Mining life cycle modelling: A cradle-to-gate approach to environmental management in the minerals industry. J. Clean. Prod. 2006, 14, 1057-1070. [CrossRef] 
22. Drielsma, J.A.; Russell-Vaccari, A.J.; Drnek, T.; Brady, T.; Weihed, P.; Mistry, M.; Perez Simbor, L. Mineral resources in life cycle impact assessment-Defining the path forward. Int. J. Life Cycle Assess. 2016, 21, 85-105. [CrossRef]

23. Burchart-Korol, D.; Krawczyk, P.; Czaplicka-Kolarz, K.; Turek, M.; Borkowski, W. Development of sustainability assessment method of coal mines. J. Sustain. Min. 2014, 13, 5-11. [CrossRef]

24. Czaplicka-Kolarz, K.; Burchart-Korol, D.; Krawczyk, P.; Turek, M.; Borkowski, W. Model of eco-efficiency assessment of mining production processes. Arch. Min. Sci. 2015, 60, 477-486. [CrossRef]

25. Stanek, W.; Czarnowska, L.; Pikoń, K.; Bogacka, M. Thermo-ecological cost of hard coal with inclusion of the whole life cycle chain. Energy 2015, 92, 341-348. [CrossRef]

26. Radović, U. Atmospheric Pollution. Sources and the Methodology of Estimating the Pollution Emission Quantities; Centrum Informatyki Energetyki: Warsaw, Poland, 1997.

27. European Commission. Available online: https://ec.europa.eu/commission/presscorner/detail/en/ip_20_416 (accessed on 15 March 2020).

(C) 2020 by the authors. Licensee MDPI, Basel, Switzerland. This article is an open access article distributed under the terms and conditions of the Creative Commons Attribution (CC BY) license (http://creativecommons.org/licenses/by/4.0/). 